fact standard symbols for various corrections to the proof, as illustrated in Fig. 1. Where long insertions are required it is best to code them using letters and to type them out separately.
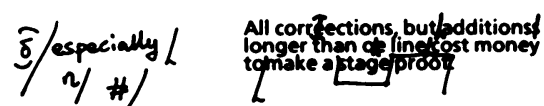
$\delta$ '

Fig. 1. An illustration of the more common proofcorrection marks.

All your marks are amalgamated onto a top set of proofs which is then returned to the typesetter to make the corrections. This is one more stage at which errors can be made, and so the publisher sees a second set of proofs (revised or page proofs). This is usually the last time the text is seen before it is printed.

Printing is mostly by lithography. The images on the photographic paper produced by the typesetter are transferred to a printing plate. This is a specially treated flexible sheet of metal, which generally holds
8,16 or 32 pages of text (which is why books sometimes have to have a few blank pages at the end). The plate is then wrapped around a cylinder on the printing machine. I digress: what better place to bring this series to its close?

\section{Practical advice}

Your work is thus available for the public to peruse. I would like to leave you with a thought at this point. The readership of the British Journal of Psychiatry is about 12,000 . If only $1 \%$ of these people read your article, any mistake would stand a chance of being spotted by some 120 people. If these people spent only 10 minutes trying to solve the mystery of an extra patient or in finding a reference you gave the wrong year for, this amounts to about 20 man-hours. These conservative figures should go to show the tenfold blessings and more that are yours if you spend a couple of hours checking through that last draft!

\section{Miscellany}

\section{Awards}

\section{The McHarg Prize}

The Scottish Division of the Royal College of Psychiatrists offers a prize of $£ 100$ to a trainee who is working in Scotland and who is of senior registrar or registrar grade. Candidates for the prize are invited to submit essays or scientific papers based on their own studies or their original work. It is expected that submissions will range from essays based on literature review to descriptions of clinical work or research in the field. All entries will be considered by a panel set up by the Scottish Executive Committee and it is intended that the successful candidate will be invited to present his paper to a meeting of the Scottish Division. Submissions must be returned before 1 December 1990 to Dr R. G. McCreadie, Honorary Secretary, Scottish Division, Royal College of Psychiatrists, Crichton Royal Hospital, Dumfries DG1 4TG.

\section{Joan Bicknell Prize}

The Psychiatry of Disability Division at St George's Hospital Medical School, University of London, invites registrars and senior registrars to submit essays on an aspect of the Psychiatry of Disability for the
Joan Bicknell Prize. The winner will be required to deliver the essay in lecture form as part of the Psychiatry of Disability's Annual Conference entitled 'Holistic Approaches to Disability and Mental Health' to an audience of 250, comprising disabled people, carers and professionals. The essay will be published as part of the conference proceedings. More information is available from Philippa Weitz, The Conference Unit, Department of Mental Health Sciences, St George's Hospital Medical School, Cranmer Terrace, London SW17 ORE (telephone 081-672 9944 extension 55534).

\section{Peter Beckett Postgraduate Research Award}

The family and friends of the late Professor Peter Beckett, former Dean of the Medical Faculty and Professor of Psychiatry, Trinity College, University of Dublin, have funded a research award to be known as the Peter Beckett Postgraduate Research Award with the purpose of encouraging research in psychiatry.

The award will be made annually on the recommendation of a committee comprising the Dean of the Medical School, the University Professor of Psychiatry, the Clinical Professor of Psychiatry and the Professor of Clinical Medicine, to the candidate 
who, in the opinion of the Committee, has carried out the best research project in psychiatry during his/her postgraduate training. The research should normally have been carried out in Ireland.

The award is open to all postgraduate trainees in psychiatry who have completed at least three years of a formal training programme approved by the Committee; its value will be approximately $£ 350$.

Applications should reach the Medical School Office, Faculty of Health Sciences, Trinity College, Dublin 2, Ireland, not later than 31 December 1990 and each candidate should submit a full written description of the completed research project which he/she wishes to have considered.

Henry Hutchinson Stewart Scholarship in Psychiatry 1990 (Trinity College, University of Dublin)

This Scholarship was founded in 1884 by a bequest from Henry Hutchinson Stewart. It is awarded annually, and is available to graduates in medicine of not more than ten years' standing. Its object is to encourage younger graduates to undertake further work in the specialised aspects of psychiatry, including the acquisition of modern techniques and the carrying out of research.

Awards are made on the recommendation of a committee, and candidates may be requested to attend for interview. Successful candidates are expected to work for at least six months under the direction of a senior member of staff in a hospital or a University department approved by the Board of the College. The work must consist of advanced study, preferably including research, and should be such as to enable the successful candidate to gain experience in modern methods of investigating disease. Approval of the Board must be obtained for any change in the agreed programme of study and research.

The value of the Scholarship for the year 1990 will be $£ 5,400$ payable in six equal monthly instalments. Scholars whose total income from all sources, including the scholarship, would exceed the top point on the salary scale for hospital Registrars are expected to declare this fact and to arrange a suitably reduced sum from the Scholarship Fund.

Littlemore Hospital Travelling Research Fellowship This fellowship offered by The Schizophrenic Research Trust (value $£ 1,500$ ) is designed for inceptors or members of the College below consultant level who are actively participating in research on topics relating to schizophrenia. It should enable them to visit centres of excellence pertinent to their research to broaden their awareness of research techniques. Applicants should include a curriculum vitae, description of current research and planned study abroad with supporting statements from the host centre and the names of two referees. Applications to Dr B. M. Mandelbrote, Littlemore Hospital, Littlemore, Oxford OX4 4XN (for the Schizophrenia Research Trust). Charity Reg. No. 327701.

\section{Papers on child abuse and child protection}

Dr J. E. Oliver has a large collection of papers and other publications on aspects of child abuse which he would like to be made available either to a person concerned with this work or to an organisation. Further information: Dr J. E. Oliver, Consultant Psychiatrist, Burderop Hospital, Wroughton, Swindon SN4 0QA.

\section{New publication}

The Wessex Memory Manual is a 32 page self-help guide for people with everyday memory difficulties. It costs $£ 1.50$, plus 50p for package and posting; cheques should be made payable to Memory Disorders Research Fund. Copies are available from: Dr N. Kapur, Wessex Neurological Centre, General Hospital, Southampton SO4 4XY.

\section{Updated publication}

The A-Z of Welfare Benefits for People with a Mental Illness has now been updated and includes some of the Government's proposals for reforming the benefit system and gives information on housing benefits, the Social Fund, Unemployment Benefit etc.; it costs $£ 1$. Copies are available from: MIND Mail Order, 4th Floor, 24-32 Stephenson Way, London NW1 2HD.

\section{British Institute of Mental Handicap}

BIMH aims to contribute to an improving quality of life for people with learning difficulties. Membership offers receipt of the quarterly journal Mental Handicap, reduced rates at most BIMH conferences, courses and workshops, advance details of all conferences, courses and workshops, access to the services provided by the Information and Resource Centre, and a vote at the AGM. Further information: Membership Secretary, BIMH, Wolverhampton Road, Kidderminster, Worcs. DY10 3PP (telephone 0562 850251). 